\title{
Design and Analysis of Metamaterial based-check board AMC Backed EBG Antenna for Body Placement Applications
}

\author{
${ }^{1}$ Kunapareddy Koteswara Rao, ${ }^{2}$ Pasumarthy Nageswara Rao, ${ }^{3}$ Vangala Sumalatha \\ ${ }^{1}$ Research Scholar, Department of ECE, JNTU Anantapur, AP, India \\ ${ }^{2}$ Professor, Department of ECE, Vardhaman College of Engineering Hyderabad \\ ${ }^{3}$ Professor, Department of ECE, JNTU Anantapur, AP, India
}

\begin{abstract}
In this paper a compact EBG antenna with Artificial Magnetic Conductor (AMC) is proposed for on body applications. The proposed antenna is designed with single SRR (split ring resonator) and double SRR to differentiate the performance of the proposed antenna. The proposed EBG antenna bending analysis is performed at different angles on human body to attain good radiation characteristics. The footprint of proposed antenna is of $0.2 \lambda_{0} * 0.24 \lambda_{0} \mathrm{~mm} 2$ and AMC with dimension of $0.48 \lambda_{0} * 0.48 \lambda_{0} \mathrm{~mm} 2$. The proposed antenna is obtained good return loss and radiation characteristics when EBG antenna is placed on the human leg with an angle of 300 at corresponding operating frequencies $2.4 \mathrm{GHz}, 5.8 \mathrm{GHz}$, $9 \mathrm{GHz}$ and $9.5 \mathrm{GHz}$ respectively. The obtained operating frequencies cover wireless applications such as GPS, ISM, and Radar and satellite communications. The proposed EBG antenna is obtained with high gain $7.05 \mathrm{dBi}$ at $9.5 \mathrm{GHz}$ operating frequency. The surface current distributions are obtained for the proposed antenna is of $137 \mathrm{~A} / \mathrm{m}$. Good isometric radiation patterns are observed for the proposed antenna. The SAR analysis is performed when the EBG antenna is placed on the human leg at an angle of 30degree is of $1.23 \mathrm{~W} / \mathrm{kg}$.
\end{abstract}

Keywords: Electromagnetic Band gap Structure (EBG), DSRR, SSRR, SAR.

DSRR : Double Split Ring Resonator

SSRR : Single Split Ring Resonator

SAR : Specific Absorption Ratio

1. Introduction:

2. The artificial magnetic conductors are becoming very popular these days because of their usage as high impedance surfaces in the design of low-profile antennas. Periodic slots on electrically thin grounded dielectric materials with Frequency Selective Surfaces are gaining their importance to act as high impedance surfaces. Active research is being carried out on AMC structures with the combination of electromagnetic band gap structures and metamaterials. For artificial magnetic conductor (AMC) has the characteristics of in-phase reflection, it can reduce the backward radiation of the antenna, consequently decreasing SAR. Compared with the antenna using conventional PEC, the antenna combining with AMC can maintain a low profile. Wearable antennas based on AMC have been proposed. In [6]-[7], a dual-band (i.e., 2.45 $\mathrm{GHz}$ and $5 \mathrm{GHz}$ ) textile antenna based on the electromagnetic band gap (EBG) is investigated. The dimension of the textile antenna is $120 \mathrm{~mm} \times 120 \mathrm{~mm}$, and especially the textile nature of fluid absorption makes the antenna gain instability under humid environment. In [8], a single band (2.45 GHz) monopole antenna integrated with a Jerusalem Cross AMC ground plane is studied. This kind of antenna can be expanded to multi-band for wide-range applications. [1-20].

Rapid developments have been taking place in the wireless communication field to fulfil the needs of the high data rates with compact modules. Antenna design is shifting towards multiband operations with high gain and large bandwidth to cater to the needs of modern communication systems [21-34]. Metamaterials are the art and heart of such antennas, whose existence in the design marking is significant with tremendous applications [15-20]. Compact antenna design for multiband applications and making it most suitable for targeted bands with greater performance characteristics is the challenging job for the researchers. Metamaterial structures are exhibiting quasi static resonant frequencies at wave lengths which are smaller than the guided wavelengths. Single split ring cell metamaterials, double split ring cell metamaterials and complementary split ring resonators are widely used structures 
IT in Industry, Vol. 9, No.2, 2021

for attaining the negative permittivity or negative permeability and negative refractive index [35-40].

In most of the biomedical applications, wearable antennas are used. For an athlete and for old aged people, wearable antennas can be used. Light in weight, low cost, almost zero maintenance and no installation procedure are some of the required features of the wearable antennas [41]. SAR is the value which describes how much power absorbed in biological tissue when the Body is exposed to electromagnetic radiation. SAR values increase as the conductivity of human body tissues increases and usually decrease as the relative permittivity of human body tissues increase. The effect of the dielectric values of human body on SAR depends on orientation of the patch on the human body and frequency [42].

The paper is aimed to analyze the performance of the antenna in terms of SAR, reflection coefficient, Gain, radiation pattern when the antenna is placed on a human body,
Published Online 1-4-2021

considering all practical cases like bending of the body parts etc.

\section{Antenna Design:}

SSRR and DSRR mainly consist of single loop and double loop which exhibits negative permittivity and negative permeability of the unit cell which improves the performance value of the antenna in terms of return loss, gain, SAR values. Fig 1(a) shows the s-shaped antenna on EBG structure. The EBG structure consists of check board shaped metal separations with metamaterial inspiration. The circular conducting structures are modeled into single split ring resonators and arranged as shown in the Figure 1(a). The Fig 1(b) shows double split ring resonators in the place of single split ring resonators. The design of SSRR and DSRR is done using FEM based tool and the metamaterial behavior is analyzed with unit cell analysis. Point type feeding technique is used for the proposed antenna.

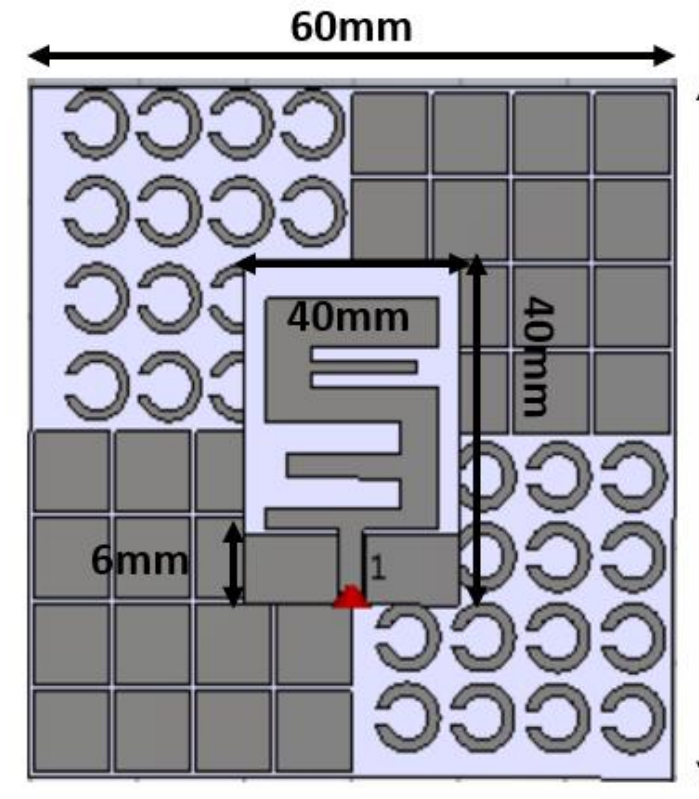

(a)

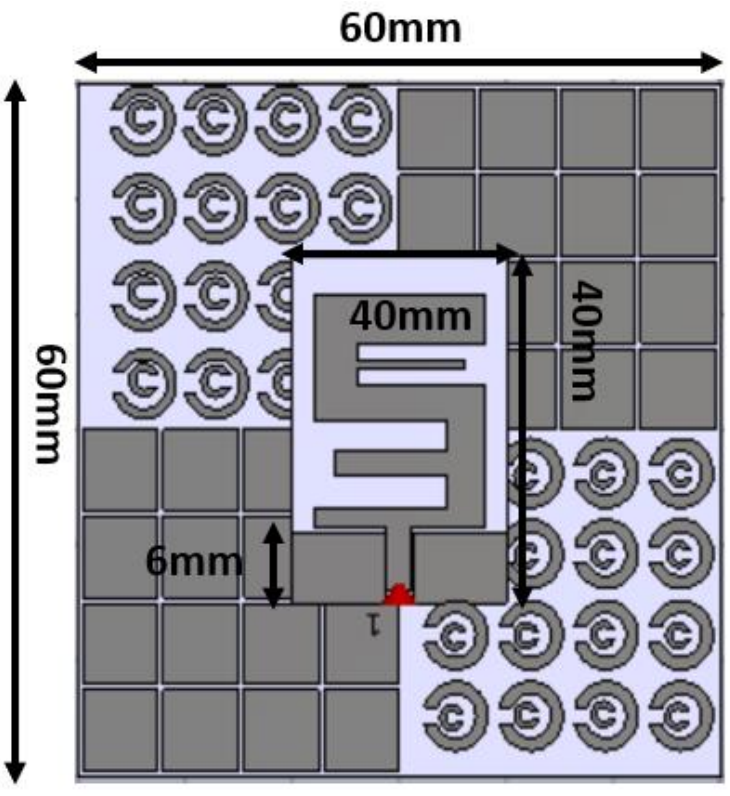

(b) 


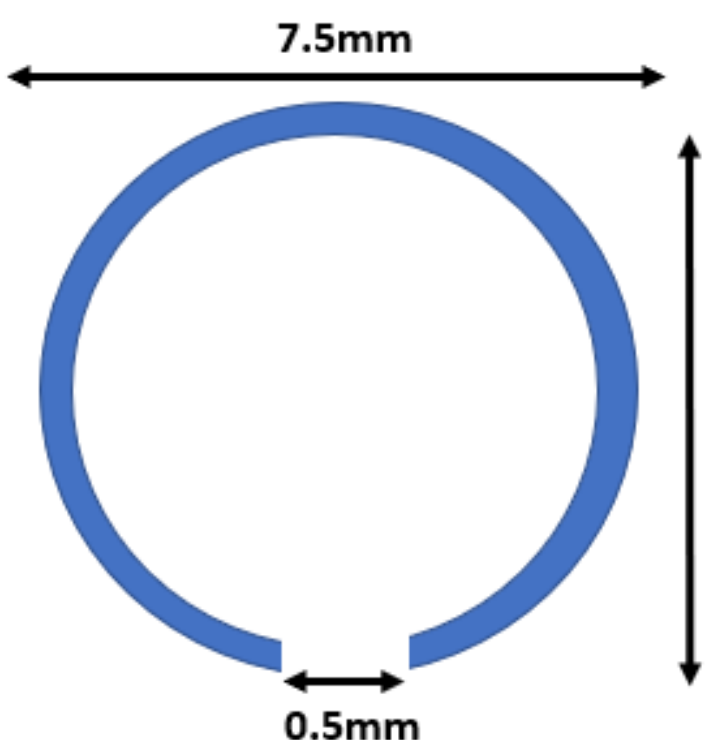

(c)

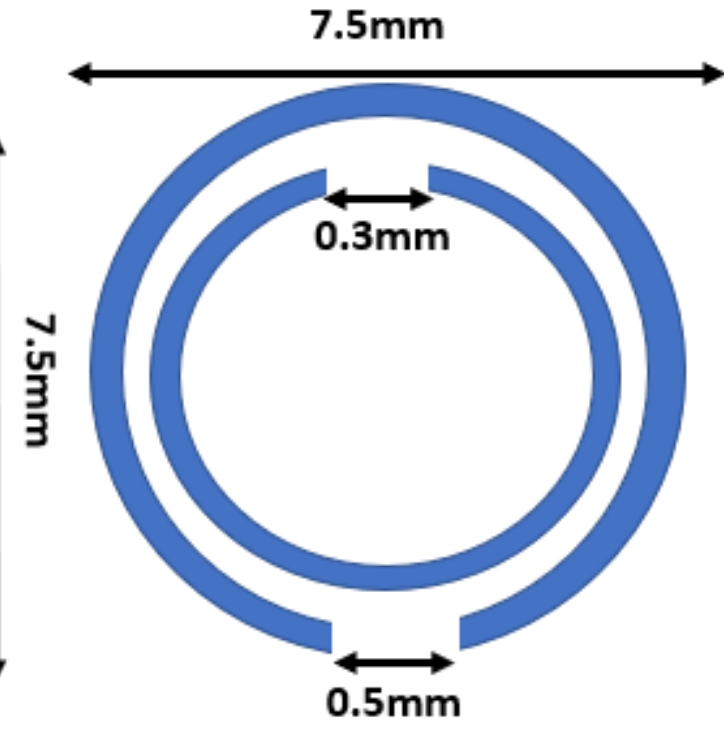

(d)

Fig 1. Proposed Antenna Models, (a) Antenna Model 1 with SSRR, (b) Antenna Model 2 with DSRR, (c) SRR and (d) DSRR

The design equations are given for calculating the total capacitance, inductance and the resonant frequency.

The total capacitance of the SRR can be calculated by

$$
c_{t}=\frac{1}{c_{s}+c_{g}+c_{c}}
$$

Inductance in the loop of the Circular SRR is calculated by

$$
L=\mu_{0} r\left(\log \left(\frac{2 r}{w}\right)+0.9+0.2\left(\frac{w}{2 r}\right)^{2}\right.
$$

Where $r$ is the radius of the circle and $w$ is the gap between the ring

Table 1. Dimensions of the proposed antenna

\begin{tabular}{|c|c|}
\hline Parameters & Dimensions(mm) \\
\hline Patch length & 39 \\
\hline Patch width & 40 \\
\hline CPW width & 6 \\
\hline CPW length & 40 \\
\hline
\end{tabular}

The resonant frequency of the SRR is calculated by

$$
w_{0}=\frac{1}{\sqrt{\left(L_{S}+4 L_{M}\right)\left(C_{S}+C_{C}+C_{G}\right)}}
$$

where $L_{S}=$ Self Inductance, $L_{M}=$ Mutual Inductance, $C_{S}=$ Surface Capacitance, $C_{C}=$ Coupling capacitance, $C_{G}=$ Gap Capacitance. 
IT in Industry, Vol. 9, No.2, 2021

\begin{tabular}{|c|c|}
\hline EBG Square unit cell width & 7.5 \\
\hline EBG Square unit cell length & 7.5 \\
\hline EBG length & 60 \\
\hline EBG width & 60 \\
\hline
\end{tabular}

\section{Result and Analysis:}

\subsection{Reflection coefficient}

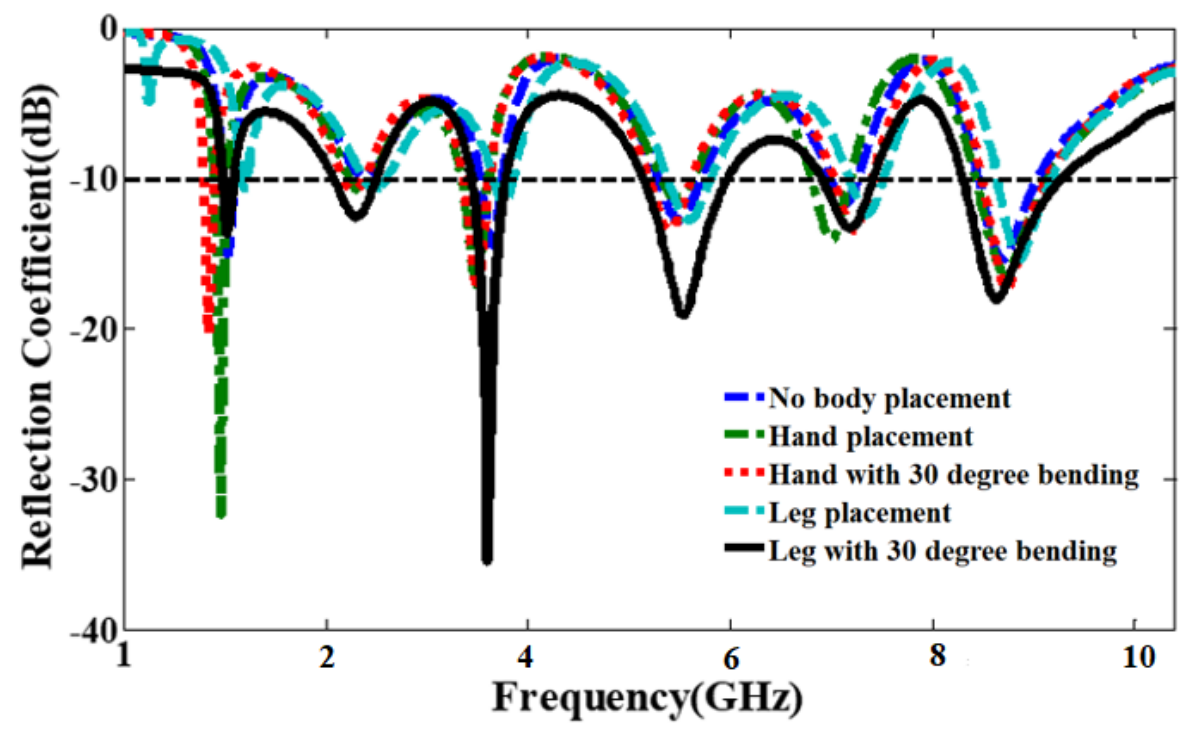

Fig.2 Measured Reflection coefficient vs Resonating frequency of Single SRR EBG antenna

The fig 2 shows a reflection coefficient value of single SRR EBG antenna at various conditions in which the antenna with a bending of 30 degree on leg stating the minimum reflection coefficient value and it was observed that antenna having minimum reflection coefficient value of $-32 \mathrm{~dB}$ at a frequency of $1.7 \mathrm{GHz}$ which was used for GPS application, Similarly, at a frequency of $4.9 \mathrm{GHz}$, it was having a reflection coefficient value of $-37 \mathrm{~dB}$ which was used for WBAN applications. Later, at a frequency of $6.3 \mathrm{GHz}$, it was having a reflection coefficient value of $-19 \mathrm{~dB}$ which was used for wireless applications. Finally, at a frequency of 8.1 and $8.5 \mathrm{GHz}$, it was having a reflection coefficient value of $-12 \mathrm{~dB}$ and $-18 \mathrm{~dB}$ which was used for satellite applications 


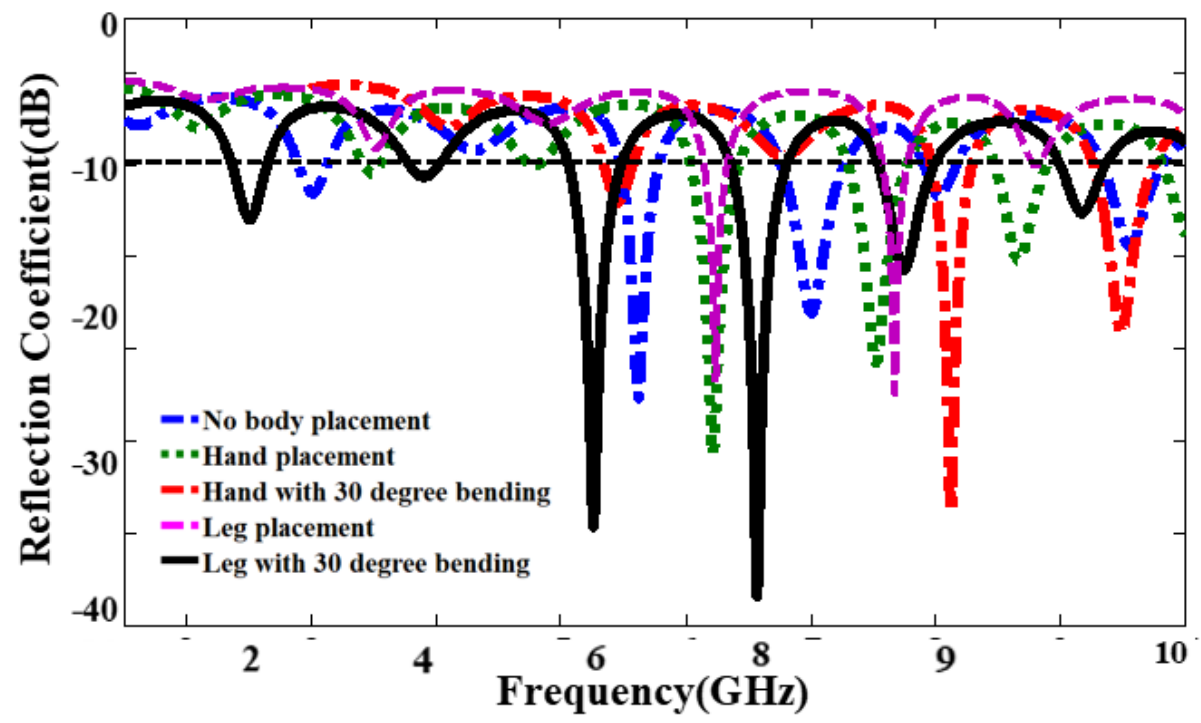

Fig.3 Measured Reflection coefficient vs Resonating frequency of Double SRR EBG antenna

The fig 3 shows reflection coefficient of double SRR EBG antenna at various conditions in which the antenna and leg bend with the inclination of 30 degree stating the minimum reflection coefficient value and it was observed that antenna was having minimum reflection coefficient value of $-14 \mathrm{~dB}$ at a frequency of $2.4 \mathrm{GHz}$ which was used for WLAN application. Similarly, at a frequency of $5.8 \mathrm{GHz}$, it was having a

\subsection{Radiation patterns}

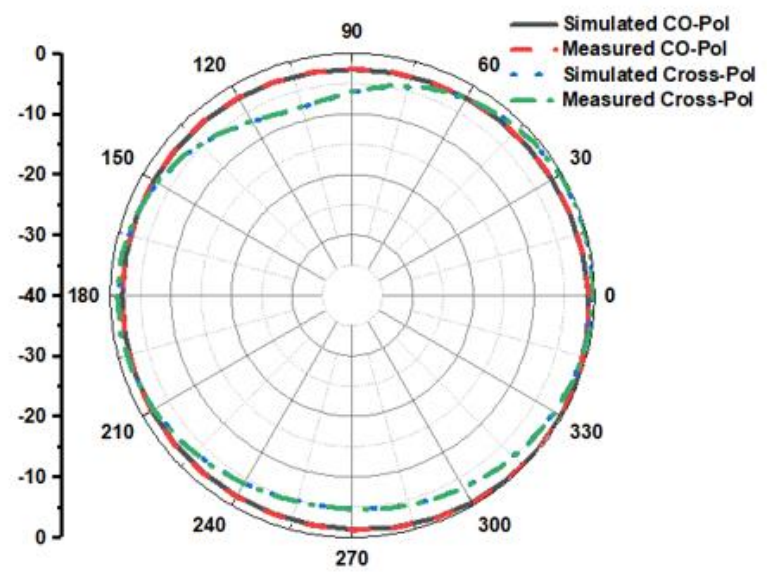

(a)At a frequency of $2.4 \mathrm{GHz}$ reflection coefficient value of $-34 \mathrm{~dB}$ which was used for ISM applications. Later, at a frequency of $8 \mathrm{GHz}$, it was having a reflection coefficient value of $-39 \mathrm{~dB}$ which was used for radar applications. Finally, at a frequency of 9 and $9.5 \mathrm{GHz}$, it was having reflection coefficient value of $-19 \mathrm{~dB}$ and $-13 \mathrm{~dB}$ which was used for satellite applications.

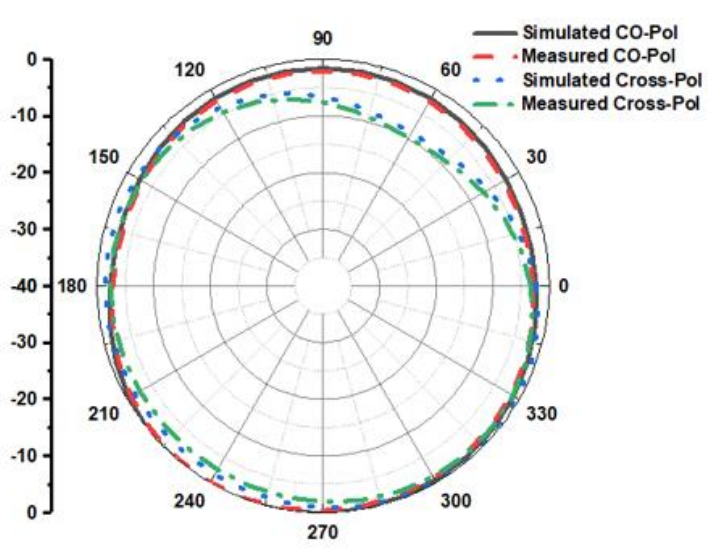

(b) At a frequency of $5.8 \mathrm{GHz}$ 


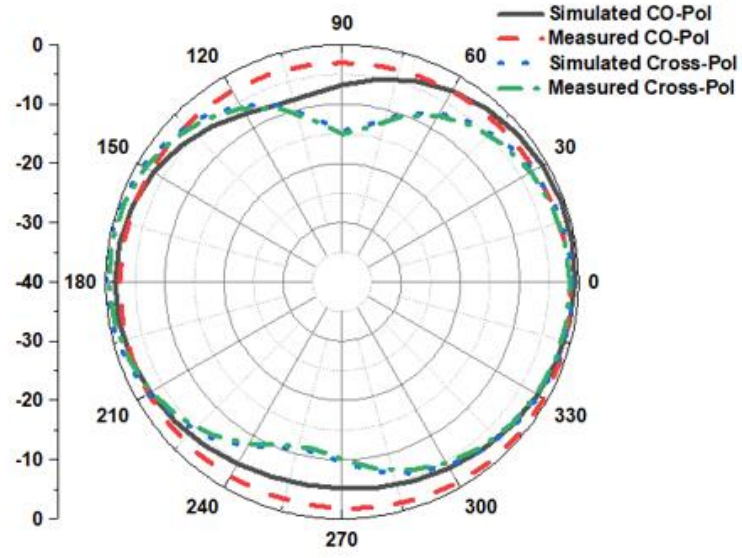

(c) At a frequency of $8 \mathrm{GHz}$

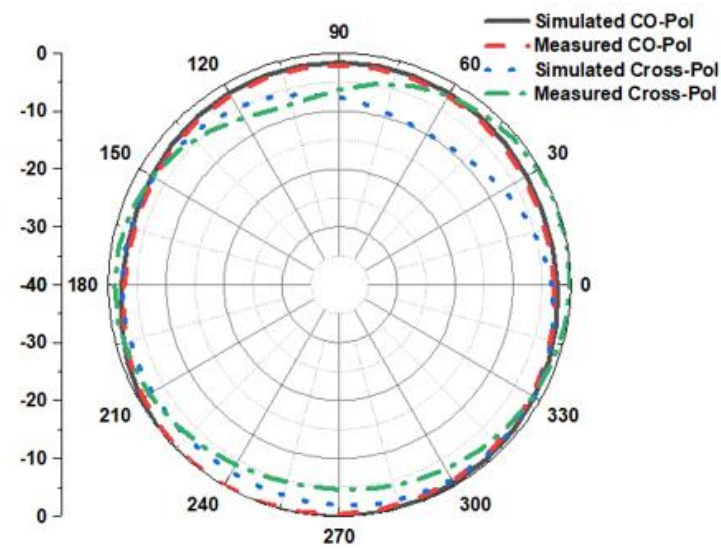

(e) At a frequency of $9.5 \mathrm{GHz}$

(f) At a frequency of $1.7 \mathrm{GHz}$

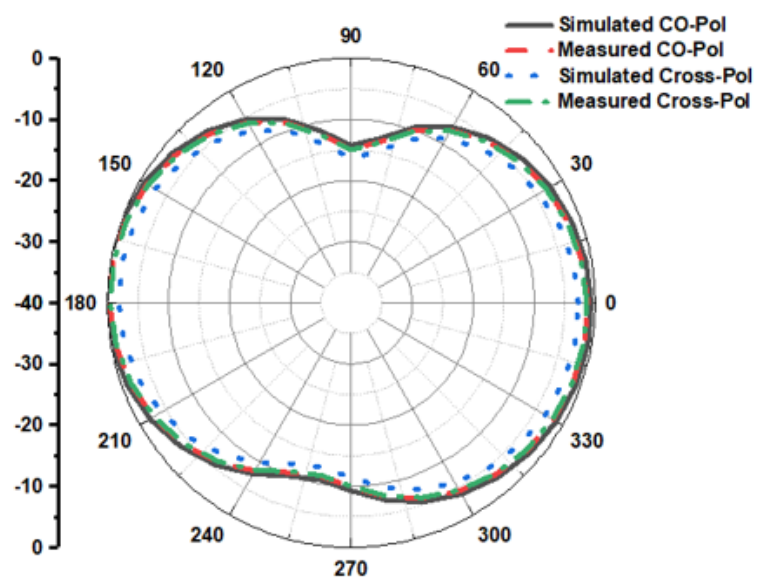

(g) At a frequency of $4.9 \mathrm{GHz}$

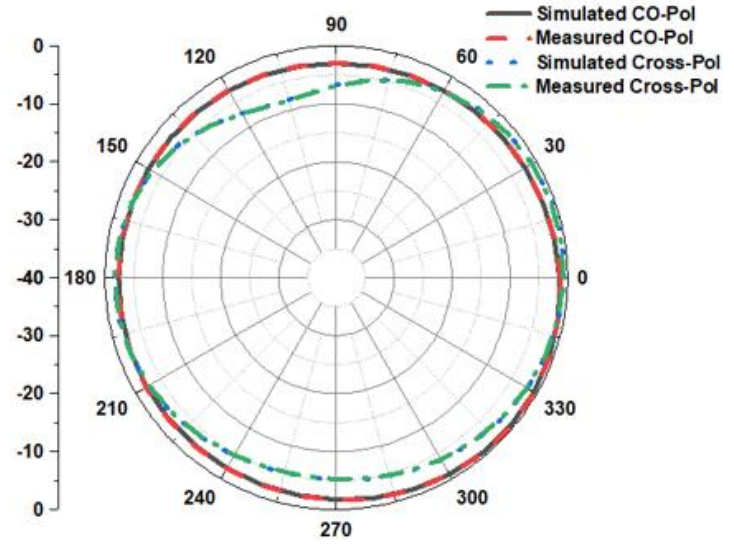

(d) At a frequency of $9 \mathrm{GHz}$
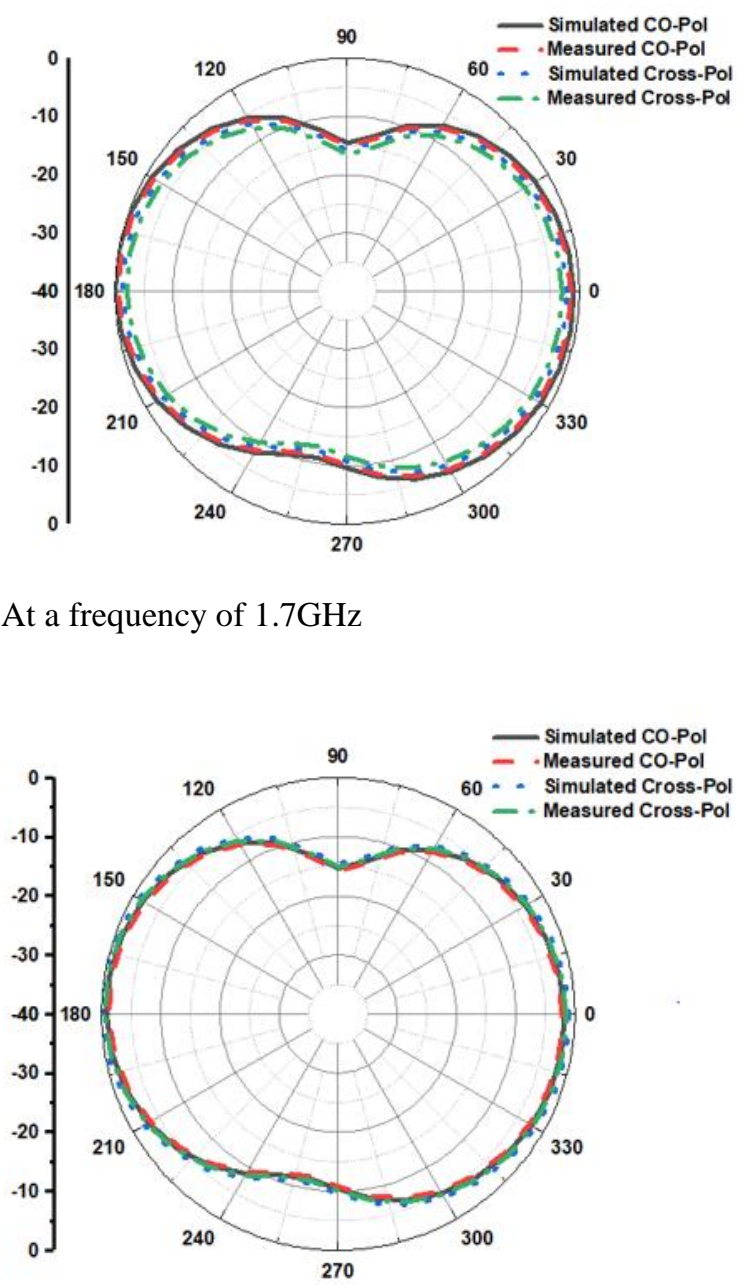

(h) At a frequency of $6.3 \mathrm{GHz}$ 

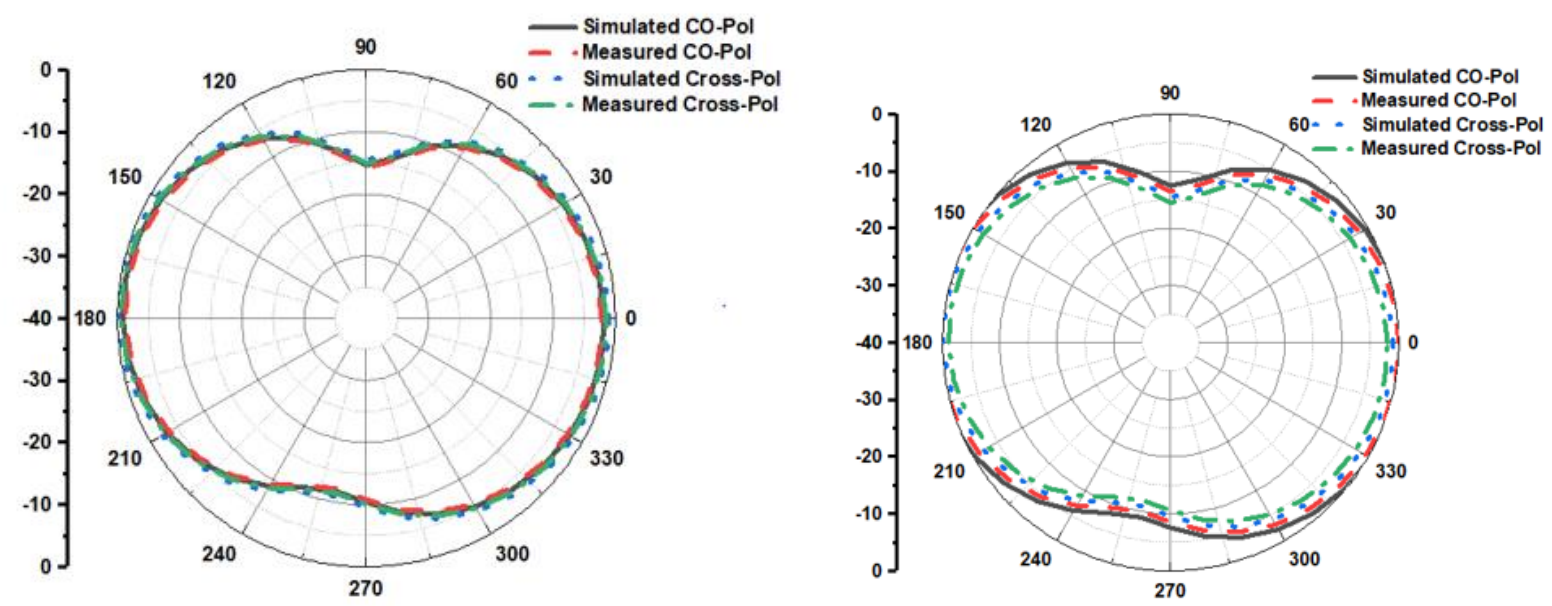

(i) At a frequency of $8.1 \mathrm{GHz}$

(j) At a frequency of $8.9 \mathrm{GHz}$

Fig 4. 2D-Radiation patterns of(a-e) Double SRR EBG and(f-j) Single SRR EBG antenna

The measured radiation patterns of the proposed double SRR are presented in Fig.4. The farfeild charatersitics of co and cross polarizations at corresponding resonant frequencies are given. The presented radiation charactersistics are in semi omni directional and omni directional for both co-polar and cross polar. The patterns are bidirectional in broad side direction and omni directional for co-polar. It is observed that the cros polar levels are $20 \mathrm{~dB}$ less than the Co-polar levels. Similarly the cross polar is omni directional and copular was like a semi omni directional and slightly converted to bidirectional shape. The patterns were at $8 \mathrm{GHz}$ and $9 \mathrm{GHz}$ and were almost like the previous bands, but the co-polar and cross polars were almost same with respect to the planes. The cross polar levels are $-15 \mathrm{~dB}$ less than co-polar level. Omni directional patterns were observed in the end fire direction for co polar and Omni directional pattern was observed for crosspolar.

\subsection{Surface current distribution}

Fig.5 states the surface current distribution of single SRR and double SRR EBG antenna. Fig.5(a) states the surface current distribution of double SRR EBG antenna at an operating frequency $2.4 \mathrm{GHz}$ with a value of $77.4 \mathrm{~A} / \mathrm{m}$ which having maximum intensity across the patch. Secondly, fig .5(b) states the surface current distribution of double SRR EBG antenna at an operating frequency $5.8 \mathrm{GHz}$ with a value of $85.1 \mathrm{~A} / \mathrm{m}$ which having maximum intensity across the patch and across the circular rings. Thirdly, fig .5(c) states the surface current distribution of double SRR EBG antenna at an operating frequency $8 \mathrm{GHz}$ with a value of $93.5 \mathrm{~A} / \mathrm{m}$ which having maximum intensity across the patch and across the circular rings. Fourthly, fig .5(d) states the surface current distribution of double SRR EBG antenna at an operating frequency $9 \mathrm{GHz}$ with a value of $107 / \mathrm{m}$ which having maximum intensity across the patch and across the circular rings. Finally, fig .5(e) states the surface current distribution of double SRR EBG antenna at an operating frequency $9.5 \mathrm{GHz}$ with a value of $137 \mathrm{~A} / \mathrm{m}$ which having maximum intensity across the patch and across the circular rings.

Similarly, Fig.5(f) states the surface current distribution of single SRR EBG antenna at an operating frequency $1.7 \mathrm{GHz}$ with a value of $69.1 \mathrm{~A} / \mathrm{m}$ which having maximum intensity across the patch. Secondly, fig .5(g) states the surface current distribution of single SRR EBG antenna at an operating frequency $4.9 \mathrm{GHz}$ with a value of $78.3 \mathrm{~A} / \mathrm{m}$ which having maximum intensity across the patch and across the circular rings. Thirdly, fig .5(h) states the surface current distribution of double SRR EBG antenna at an operating frequency $6.3 \mathrm{GHz}$ with a value of $79.6 \mathrm{~A} / \mathrm{m}$ which having maximum intensity across the patch and across the circular rings. Fourthly, fig .5(i) states the surface current distribution of double SRR EBG antenna at an operating frequency $8.1 \mathrm{GHz}$ with a value of $80.6 / \mathrm{m}$ which having maximum intensity across the patch and across the circular rings. Finally, fig .5(j) states the surface current distribution of double SRR EBG antenna at an operating frequency $8.9 \mathrm{GHz}$ with a value of 81.2 
IT in Industry, Vol. 9, No.2, 2021

$\mathrm{A} / \mathrm{m}$ which having maximum intensity across the patch and across the circular rings.

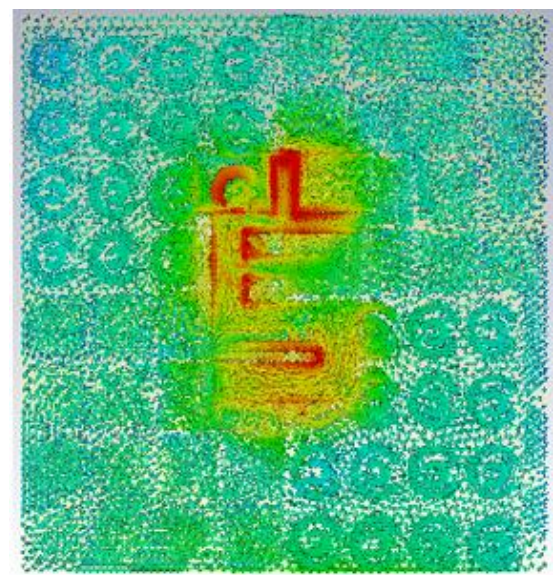

\section{$\mathrm{A} / \mathrm{m}(\log )$}

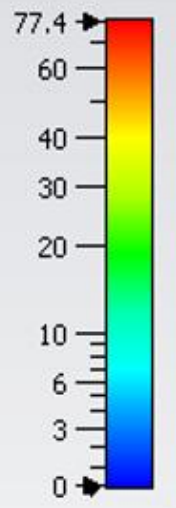

(a) At a frequency of $2.4 \mathrm{GHz}$

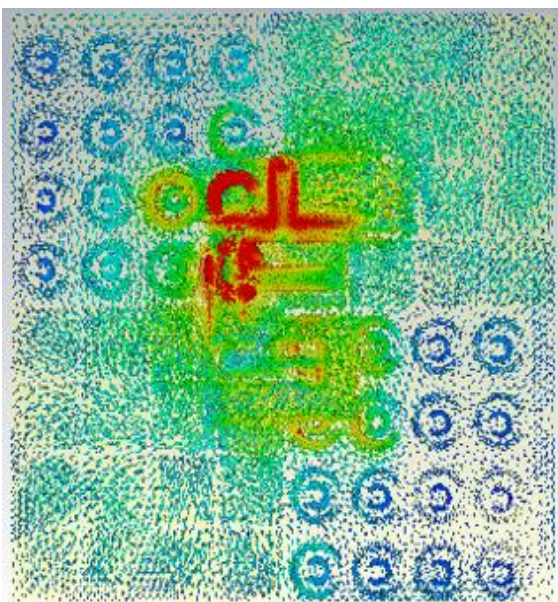

\section{$A / m(\log )$}

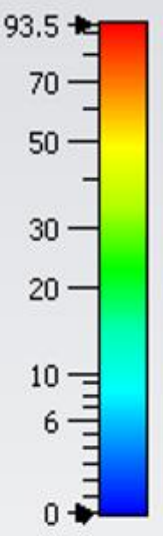

(c) At a frequency of $8 \mathrm{GHz}$
Published Online 1-4-2021

Finally, from the fig 5 (a-j) it is observed that the double SRR EBG antenna having high current distribution than the single SRR EBG antenna as the frequency shift from right to left.

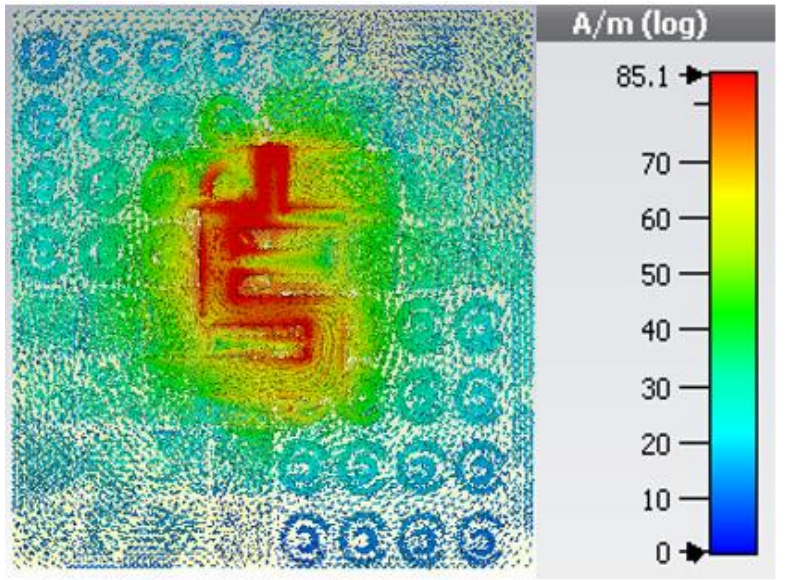

(b) At a frequency of $5.8 \mathrm{GHz}$

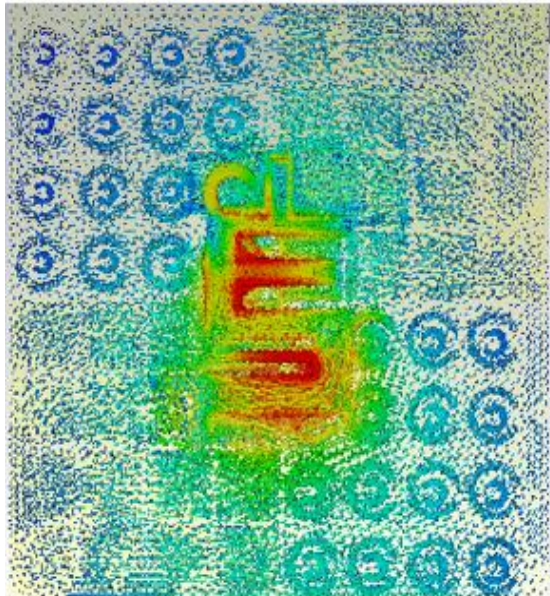

$A / m(\log )$

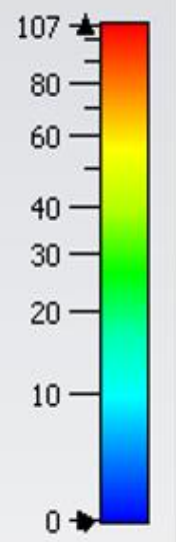

(d) At a frequency of $9 \mathrm{GHz}$ 
IT in Industry, Vol. 9, No.2, 2021

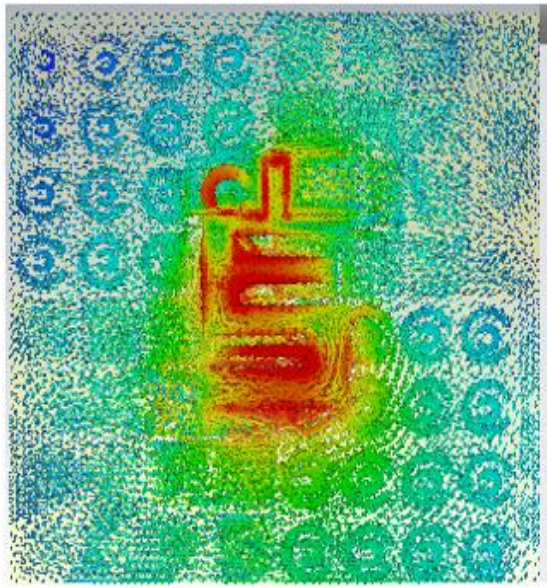

(e) At a frequency of $9.5 \mathrm{GHz}$

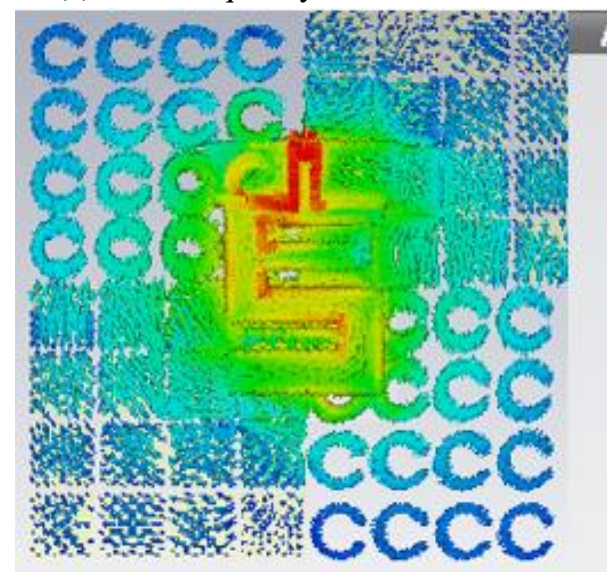

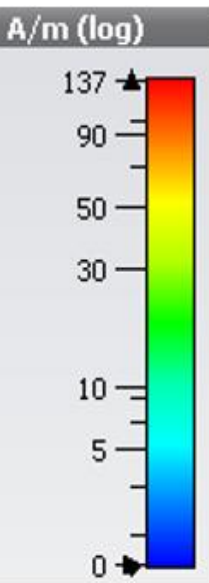

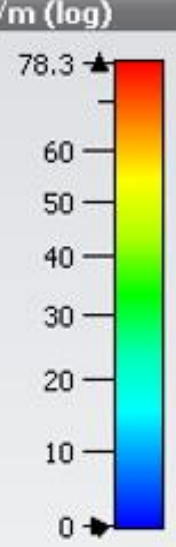

(f) At a frequency of $1.7 \mathrm{GHz}$

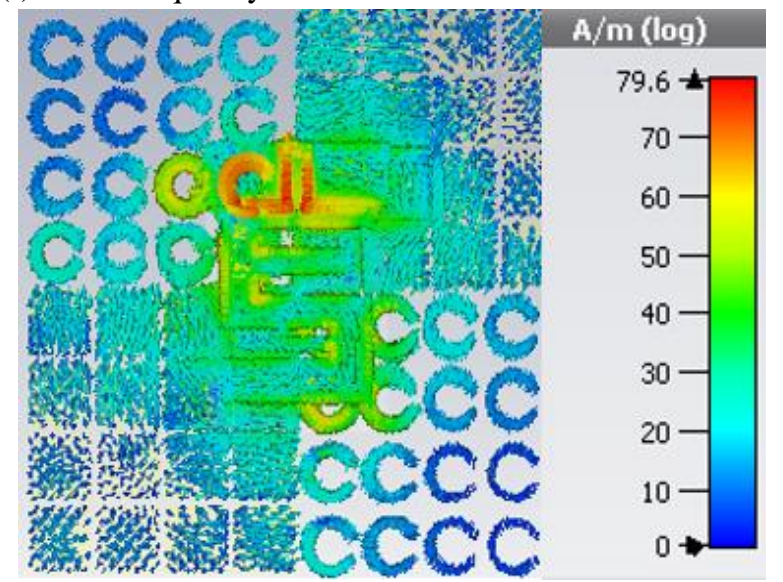

(g) At a frequency of $4.9 \mathrm{GHz}$

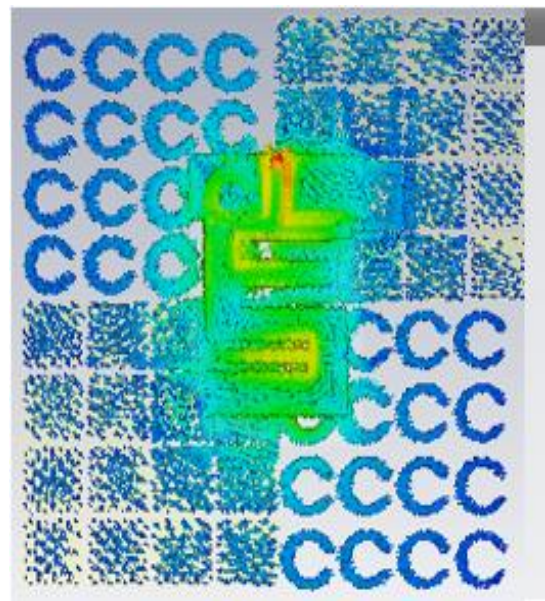

(i) At a frequency of $8.1 \mathrm{GHz}$
Published Online 1-4-2021

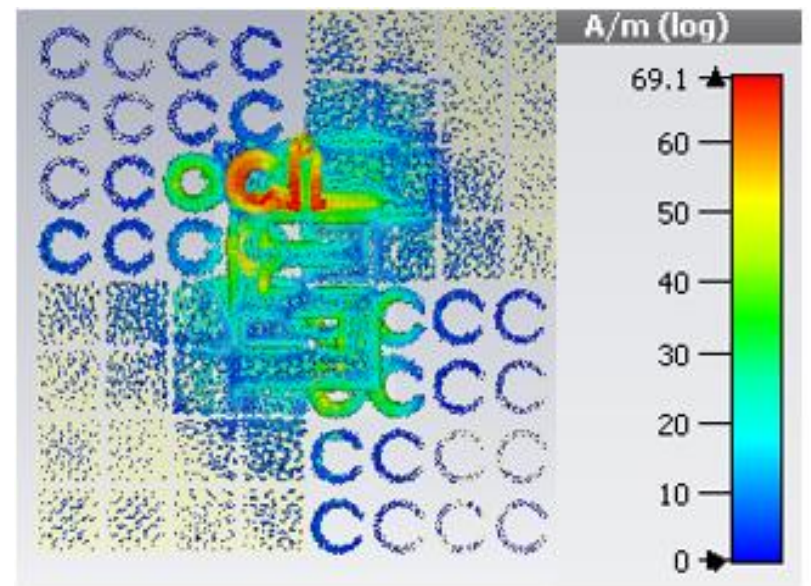

(h) At a frequency of $6.3 \mathrm{GHz}$

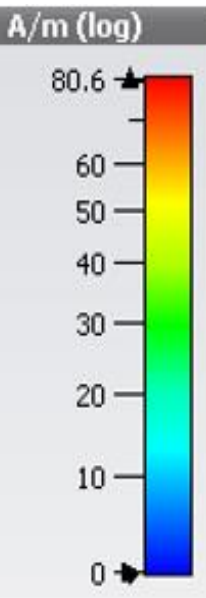

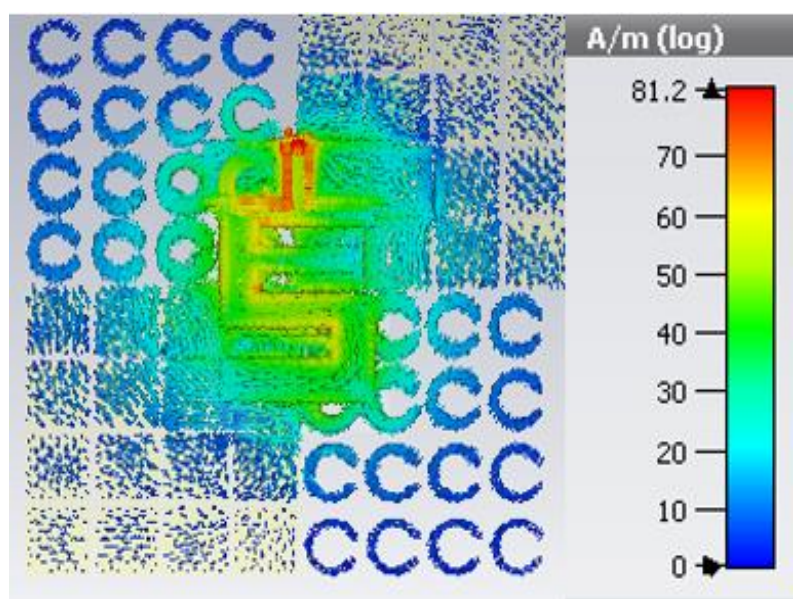

(j) At a frequency of $8.9 \mathrm{GHz}$

Fig 5. Surface current distribution of (a-e) Double SRR EBG and (f-j) Single SRR EBG antenna

\subsection{Phase velocity and Group delay}

The phase velocity is given by 


$$
v_{p}=\frac{\omega}{k}
$$

The group velocity is given by

$$
v_{g}=\frac{d \omega}{d k}=v_{p}+k \frac{d v_{p}}{d k}
$$

The group delay is given by

$$
\tau_{g}=\frac{1}{v_{g}}
$$

From equation 6 it was observed that phase velocity is inversely proportional to the group delay as phase velocity increases the group delay value decreases. Minimum group delay makes maximum stability to the device.

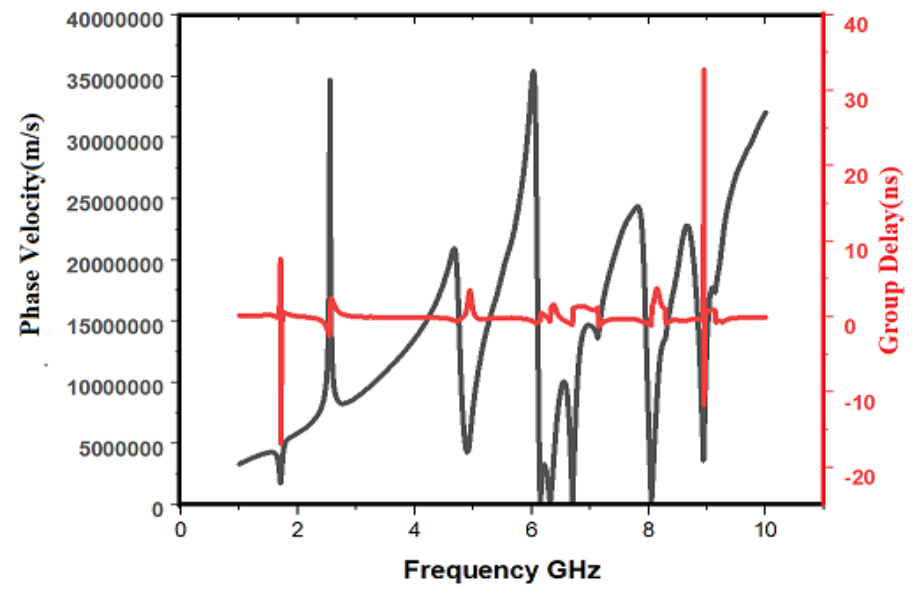

Fig 6. Frequency Vs Phase velocity and Group delay

Fig.6 states the phase velocity and group delay value of double SRR EBG antenna at various operating frequency. As the frequency shifts from right to left there is a minor nonlinearity in the phase velocity. Similarly, as the group delay value of the proposed antenna having minimum which are in terms of nano seconds.

\subsection{Specific Absorption Rate}

The human body also has some effects on the antenna as it very closely located to the human body. The human body is lossy and disturbs the communication link between antenna and outside world. The human body impact on the antenna is of different types. The human body induced gain is the ratio of gains (in $\mathrm{dB}$ ) between body-worn antenna and that of the antenna in free space. Human body has various tissues with various dielectric properties. Also the electrical properties on different frequencies have different values, the gain of the antenna is affected. So the gain of the wearable antenna differs from that of a normal antenna. The human body-worn efficiency is the ratio of total radiated power when antenna is worn in the body to the total radiated power in free space isolation. The overall power loss in a human body can be represented by this. The input impedance of the antenna will be low when the user is too close to the antenna. Also, the input impedance is dependent on the moisture conditions of the human body. And the position of the placement of the antenna.

According to the set worldwide rules, most extreme suitable SAR to protect the human security more than $10 \mathrm{~g}$ contiguous tissue is under $2 \mathrm{~W} / \mathrm{kg}$. The rules given by the IEEE C95-12005 norms say the $10 \mathrm{~g}$ of the tissue looking like cube shape should be under $2 \mathrm{~W} / \mathrm{kg}$. Net input power set to the antenna is $1 \mathrm{w}$. For the calculation of specific absorption rate formula is given by

$S A R=\int \frac{\sigma(r)|E(r)|^{2}}{\rho(r)} d r(1)$

Where $\sigma$ is electric conductivity, $\rho$ is sample density and $\mathrm{E}=\mathrm{RMS}$ electric field of the sample. 


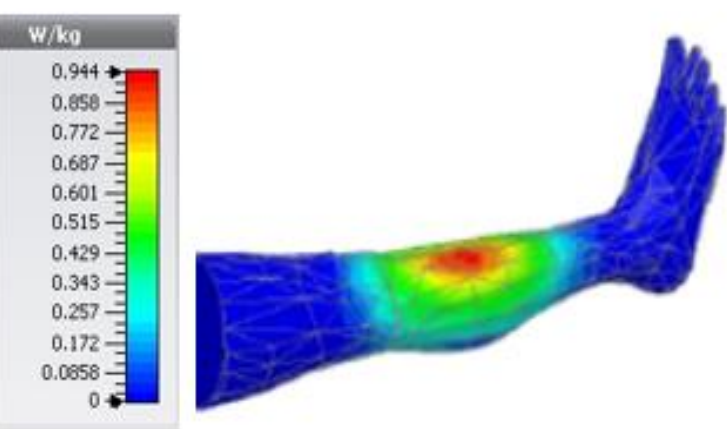

(a)

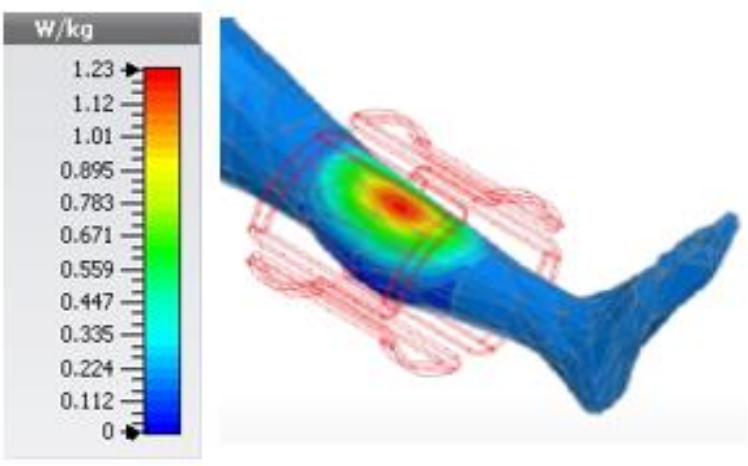

(b)

Fig 7. Specific absorption rate of proposed Double SRR EBG antenna (a) without bending and (b) with $30^{\circ}$ bending

Fig.7 states the SAR of the proposed double SRR EBG antenna with and without inclination. We have used SRR EBG technique for the proposed antenna in order to reduce the SAR. Initially fig 7(a) state the SAR of the double SRR EBG antenna on the leg without inclination having the value of $0.944 \mathrm{~W} / \mathrm{kg}$. Similarly, Fig 7(b) states the SAR of the double SRR EBG antenna on the leg with an inclination of 30 degree.
Hear both leg and antenna is inclined with an angle of 30 degree, the SAR rate of the proposed antenna with a value of $1.23 \mathrm{~W} / \mathrm{Kg}$ at an operating frequency of 5.8Ghz. As the inclination increases the value of SAR decreases. Lower the SAR lower the radiations effects which were within the threshold rate as per IEEE standards.

\subsection{Prototype model of Double SRR antenna with leg placement}

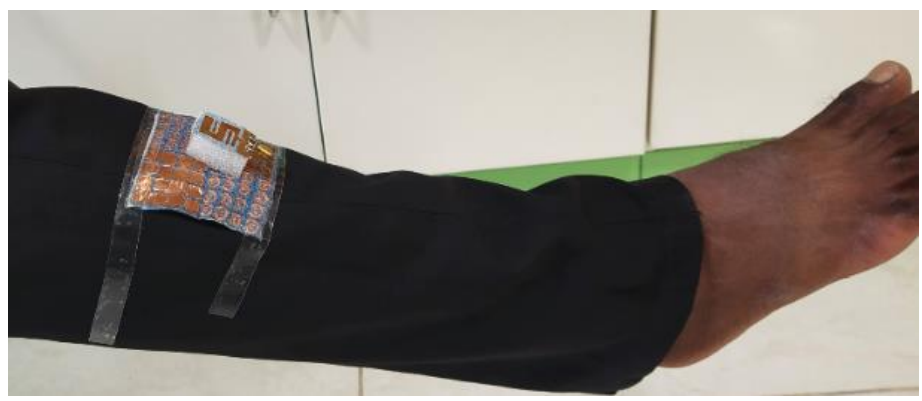

(a) 


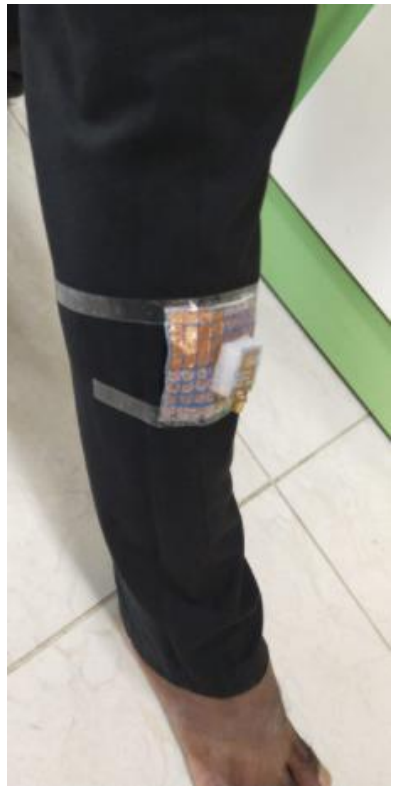

(b)

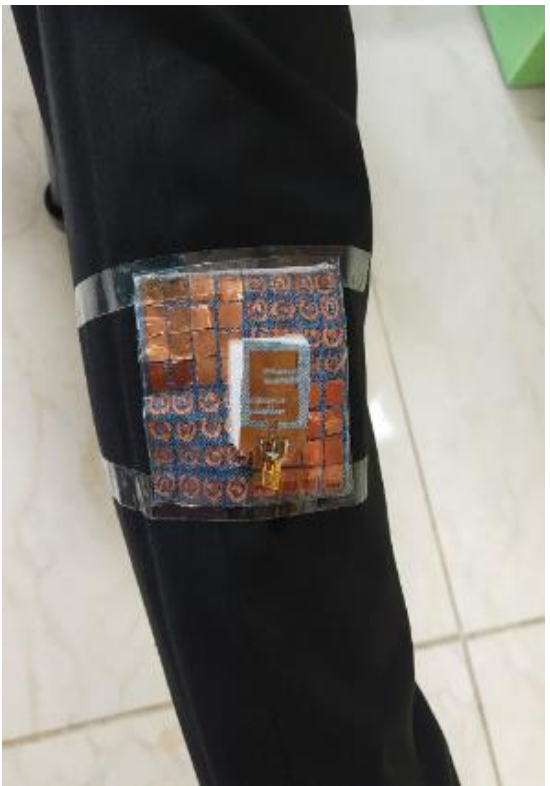

(c)

Fig 8. Prototype model of proposed double SRR EBG antenna on leg (a) without and (b) with inclination of 30 deg and (c) zoom section of the proposed antenna on leg

Fig. 8 states the placement of the proposed antenna on the leg. Initially, fig 8(a) states the placement of the proposed antenna on leg without inclination of both leg and antenna. Secondly, fig 8(b) states the placement of the proposed antenna on leg with the inclination of 30 degree. Finally, fi 8(c) states the zoom section of the antenna proposed antenna on the leg.

Table 2. Comparison of proposed antenna with previous work

\begin{tabular}{|c|c|c|c|c|c|}
\hline Ref & $\operatorname{Size}\left(\lambda_{0}\right)$ & Frequency range $(\mathrm{GHz})$ & Peak gain(dbi) & $\mathrm{SAR}(\mathrm{W} / \mathrm{kg})$ & Applications \\
\hline 43 & $\begin{array}{l}0.511 \lambda_{0} * 0.7 \lambda_{0 *} 0.0 \\
05 \lambda_{0}\end{array}$ & $1.78-1.98,2.38-2.505$ & $10.92,5.08$ & $5.77,6.62$ & GS, ISM \\
\hline 44 & $\begin{array}{l}0.25 \lambda_{0} * 0.375 \lambda_{0} * 0 \\
026 \lambda_{0}\end{array}$ & $2.4-2.4855 .725-5.875$ & $3.4,2.5$ & - & ISM \\
\hline 45 & $\begin{array}{l}0.42 \lambda_{0} * 0.44 \lambda_{0 *} 0.0 \\
09 \lambda_{0}\end{array}$ & $0.38-0.47,2.27-2.57$ & $12.4,16.1$ & $5.42,4.70$ & MICS and ISM \\
\hline 46 & $\begin{array}{l}0.33 \lambda_{0} * 0.33 \lambda_{0 *} 0.0 \\
35 \lambda_{0}\end{array}$ & $0.4-0.405,2.35-2.57$ & $1.2,8.9$ & $0.05,1.13$ & MICS and ISM \\
\hline 47 & $\begin{array}{l}0.36 \lambda_{0} * 0.36 \lambda_{0} * 0.0 \\
08 \lambda_{0}\end{array}$ & $\begin{array}{l}1.54-1.62,2.67- \\
2.87,3.33-3.46,5.24- \\
5.42\end{array}$ & $5,7.2,3 \cdot 8 \cdot 3 \cdot 7$ & $0.2,0.6,0.3$ & $\begin{array}{l}\text { GPS, Wi-Max and } \\
\text { Wi-Fi }\end{array}$ \\
\hline $\begin{array}{l}\text { Propos } \\
\text { ed } \\
\text { work }\end{array}$ & $\begin{array}{l}0.2 \lambda_{0} * 0.24 \lambda_{0} * 0.08 \\
\lambda_{0}\end{array}$ & $2.4,5.8,8,9 \& 9.5$ & $\begin{array}{l}4.1,4.2,5.7,6.9 \& \\
7.02\end{array}$ & $\begin{array}{l}0.944,1.23 \text { at } \\
5.8 \mathrm{GHz}\end{array}$ & $\begin{array}{l}\text { GPS, ISM, Radar } \\
\text { and Satellite }\end{array}$ \\
\hline
\end{tabular}


IT in Industry, Vol. 9, No.2, 2021

\section{Conclusion:}

This article presents an AMC based electromagnetic band-gap (EBG) antenna made of textile materials. The proposed wearable antenna works at IEEE standard communication applications operates at $2.4 \mathrm{GHz}, 5.8 \mathrm{GHz}, 9 \mathrm{GHz}$ and $9.5 \mathrm{GHz}$ frequency respectively. Considering the effects of single SRR and double SRR have differentiation in radiation characteristics, when the wearable antenna is placed on the human body. A comparative study is performed for the single SRR and double SRR to validate the EBG antenna. The wearable antenna achieves gain of $7.02 \mathrm{dBi}$ and with minimum absorption rate of $1.23 \mathrm{~W} / \mathrm{Kg}$ at $9.5 \mathrm{GHzoperating}$ frequency. The proposed EBG antenna is an excellent candidate for the GPS, ISM, RADAR and satellite applications with good gain and radiation characteristics. A prototype of the proposed EBG antenna is designed, fabricated and measured using ANRITSU-MS2037C combinational analyzer. The experiment results are matched with the simulated results.

\section{References:}

[1] Krishnam Naidu Yedla, G.S., Kumar, K.V.V., Rahul, R., , "Fractal aperture EBG ground structured dual band planar slot antenna", International Journal of Applied Engineering Research, ISSN 0973-4562, Volume 9, Number 5, Jan-2014, pp 515-524.

[2] VGKM Pisipati, Habibulla Khan, D Ujwala, " Fractal shaped Sierpinski on EBG structured ground plane”, Leonardo Electronic Journal of Practices and Technologies, ISSN 15831078, Issue 25, July-December 2014, pp 26-35

[3] M S S S Srinivas, T V Ramakrishna, N Bhagyalakshmi, S Madhavi, K Venkateswarulu, "A Novel Compact CPW Fed Slot Antenna with EBG Structure", ARPN Journal of Engineering and Applied Sciences, ISSN 1819-6608, Vol. 10, No. 2, Feb-2015, pp 835-841

[4] D. Naga Vaishnavi, G. Vanaja, G. Jayasree and S. Mounika, Design and analysis of metamaterial antenna with EBG loading, Far East Journal of Electronics and Communications, ISSN: 0973-7006, Vol 14, No 2, 2015, pp 127-136. http://dx.doi.org/10.17654/FJECJun2015_127_136

[5] Mounika Sanikommu, M. N. V. S. Pranoop, K. S. N. Manikanta Chandra Bose and B. Sriram Kumar, CPW Fed Antenna for Wideband Applications based on Tapered Step Ground and EBG Structure, Indian Journal of Science and Technology, ISSN: 0974-6846, Vol 8, Issue 9, May 2015, pp 119-127.

[6] CH Deepthi, T V Rama Krishna, B Prudhvi Nadh, Planar Monopole Antenna with Compact EBG For Wireless Body Area Network (WBAN) Applications, International Journal of
Published Online 1-4-2021

Recent Technology and Engineering Vol 7, Issue 6, March 2019, pp 309-313.

[7] M. L. S. N. S. Lakshmi, Habibulla Khan, P. Pardhasaradhi, EBG Loaded Compact Wide-Notch Band Antenna with Frequency Reconfigurable Characteristics, Journal of Engineering Science and Technology Vol. 14, No. 4, 2019, Pp $1852-1865$.

[8] Raghavaraju Aradhyula, T V Rama Krishna, Gain Enhancement Modelling of Coplanar Waveguide fed Circular Monopole Antenna with EBG Placement, International Journal of Engineering and Advanced Technology, Volume-8, Issue-6, August 2019, pp 1986-1991.

[9] T Anilkumar, Yepuri Spoorthi Hawanika, M Venkateswara Rao, B Prudhvi Nadh, Flexible Liquid Crystal Polymer Based Conformal Fractal Antenna for Internet of Vehicles (IoV) Applications, International Journal of Microwave and Optical Technology, Vol 14, No 6, Nov 2019, pp 423-430.

[10] T. Anilkumar, Sarat K. Kotamraju, Transparent and conformal wheel-shaped fractal antenna for vehicular communication applications, AEU-International Journal of Electronics and Communications, ISSN: 1434-8411, Vol 91, 2018, pp 1-10.

[11] M Venkateswara Rao, T Anilkumar, Conformal Band Notched Circular Monopole Antenna Loaded with Split Ring Resonator, Wireless Personal Communications, ISSN: 1572834X, 2018, pp 1-12, https://doi.org/10.1007/s11277-0185890-3.

[12] Yalavarthi Usha Devi, Mulpuri S. S. Rukmini, A Compact Conformal Printed Dipole Antenna for 5G Based Vehicular Communication Applications, Progress in Electromagnetics Research C, Vol. 85, pp 191-208, 2018.

[13] Y Usha Devi, M S S Rukmini, Liquid crystal polymer based flexible and conformal 5G antenna for vehicular communication, Materials Research Express, Vol 6, No 1, 2019, pp 1-12.

[14] Usha Devi Y, Anil Kumar T, Sri Kavya Ch K \& Pardhasaradhi P, Conformal Printed MIMO Antenna with DGS for Millimeter Wave Communication Applications, International Journal of Electronics Letters, 2019, DOI: 10.1080/21681724.2019.1600731.

[15] M Venkateswara Rao, Krishna J, Usha Devi Y, Anil Kumar, Prudhvi Nadh B, CSRR-loaded T-shaped MIMO antenna for 5G cellular networks and vehicular communications, International Journal of RF and Microwave Computer Aided Engineering, 2019, DOI: 10.1002/mmce. 21799.

[16] B Prudhvi Nadh, M Siva Kumar, Design and analysis of dual band implantable DGS antenna for medical applications, 
IT in Industry, Vol. 9, No.2, 2021

Sadhana, 2019, Vol 44, No 6, https://doi.org/10.1007/s12046-019-1099-8

[17] Ch. Sai Sree, B. Prudhvi Nadh, A New Monopole Antenna Design for ISM Band Coverage, International Journal of Recent Technology and Engineering, Volume-7, Issue-6S, March 2019, 1005-1008.

[18] S S Mohan Reddy, A Manjusha, K Aruna Kumari, B Prudhvi, Circular Ring Loaded Flower Shaped Antenna for Triple Band Applications, International Journal of Engineering and Advanced Technology, Volume-8 Issue-4, April 2019, pp 1618-1622.

[19] Venkateswara Rao M, Anilkumar T, Prudhvinadh B, Circularly polarized flexible antenna on liquid crystal polymer substrate material with metamaterial loading, Microwave and Optical Technology Letters, 2019, pp 1-9, https://doi.org/ 10.1002/mop.32088.

[20] M. Monika, B. M. Siva Kumar, B. Prudhvinadh, Dual Band Reconfigurable Compact Circular Slot Antenna for WiMAX and X-Band Applications, Radioelectronics and Communications Systems, 2019, Vol. 62, No. 9, pp. 474-485.

[21] T. Anilkumar, M. Venkateswara Rao, B. Prudhvi Nadh, Bandwidth Reconfigurable Antenna on a Liquid Crystal Polymer substrate for Automotive Communication Applications, International Journal of Electronics and Communications (2020), doi: https://doi.org/10.1016/j.aeue.2020.153096.

[22] V.G.K.M. Pisipati, Habibulla Khan, V.G.N.S. Prasad, K. Praveen Kumar, K.V.L. Bhavani and P.V. Datta Prasad, "Microstrip 2x2 Square Patch Array Antenna on K15 Liquid Crystal Substrate", International Journal of Applied Engineering Research, ISSN 0973-4562 Volume 6, Number 9 (2011) pp. 1099-1104.

[23] D S Ramkiran, Nimmagadda Haritha, R Sree Ramya, Kalyani M. Vindhya, Sai P Abhishek, "Design and analysis of microstrip slot array antenna configuration for bandwidth enhancement", Leonardo Electronic Journal of Practices and Technologies, ISSN 1583-1078, Issue 25, July-December 2014, pp 72-83.

[24] S.S. Mohan Reddy, J. Ravindranath Chowdary, V. Vinod Babu, S.S. Satya Parthiva, S. Kalyana Saravana, "Analysis of Dual Feed Asymmetric Antenna", International Journal of Applied Engineering Research, ISSN 0973-4562 Volume 8, Number 4, June-2013, pp. 361-367.

[25] Suraj Chhatkuli, A. Manikantaprasanth, Y. Bhargav, U. Dinesh Naga Venkata Sai, Syed Feeraz, "Measurement of Dimensional Characteristics of Microstrip Antenna based on Mathematical Formulation", International Journal of Applied Engineering Research, ISSN 0973-4562, Volume 9, Number 9, March-2014, pp. 1063-1074.
Published Online 1-4-2021

[26] M Ajay babu, D Naga Vaishnavi, P Radhakrishna, N Bharath, K Madhuri, K Bhavani Prasad, K Harish, Flared VShape Slotted Monopole Multiband Antenna with Metamaterial Loading, International Journal of communications Antenna propagation, ISSN: 2039-5086, Vol 5, No 2, July-2015, pp 93-97.

[27] M. Manjeera, M. S. Navya, D. Sharada Devi, V. Sumanth, Novel Metamaterial Loaded Multiband Patch Antenna, Indian Journal of Science and Technology, ISSN: 0974-6846, Vol 9, Issue 37, DOI: 10.17485 / ijst /2016 /v9i37/93378, October-2016, pp 1-9.

[28] B. L. Prakash, T. Lokesh, Y. Rajitha Sri, N. V. D. S. Aditya and M. Venkateswara Rao, Metamaterial Inspired TriBand Antenna with SRR and Shorting Stub, ARPN Journal of Engineering and Applied Sciences, ISSN:1819-6608, Vol. 12, No. 21, 2017, pp 6197-6205.

[29] K Thirumalarao, M Venkateswara Rao, V N V Saiteja, J Kranthi Kumar, P N V S Reavanth, Metamaterial inspire multiband monopole antenna with defected ground structure, International Journal of Engineering \& Technology, Vol 7, 2018, pp 90-96.

[30] V Subbareddy, M Venkateswara Rao, Y N Mahalakshmi, Shaik Hasanjama, Chaluvadi, N V S Renuka, M V V Rameswara Rao, A High Gain Metamaterial Inspired Vivaldi Antenna for Ultrawide Band Applications, Journal of Advanced Research in Dynamical and Control Systems, Vol 9, Issue 14, 2017, pp 2078-2086.

[31] Pronami Bora, Mona Mudaliar, Yuvraj Baburao Dhanade, K. Sreelakshmi, Chayan Paul, Metamaterial extended CSRR based monopole antenna for wideband applications, International Journal of Engineering and Technology, Vol 7, Issue 1.1, 2018, pp 461-465.

[32] M Venkateswara Rao, Compact Metamaterial Inspired Periwinkle Shaped Fractal Antenna for Multiband Applications, International Journal of Engineering and Technology, Vol 7, Issue 1.1, 2018, pp 507-512.

[33] Venkateswara Rao M, Anil Kumar T, Prudhvi Nadh B, Metamaterial inspired quad band circularly polarized antenna for WLAN/ISM/Bluetooth/WiMAX and satellite communication applications, AEU - International Journal of Electronics and Communications, Vol 97, 2018, pp 229-241.

[34] Pardhasaradi Pokkunuri, Gullapalli Kesava Sai, ManikondaVenkateswararao, Bonthu Ganesh, Nimmagadda Tarakaram, Dangeti Pavana Teja, Metamaterial Inspired Reconfigurable Fractal Monopole Antenna for Multiband Applications, International Journal of Intelligent Engineering and Systems, Vol.12, No.2, 2019, pp 53-61.

[35] Kishore M P, Rao M V, A CPW-fed elliptically curved antenna design for multiband operation with metamaterial 
IT in Industry, Vol. 9, No.2, 2021

loading, International Journal of Innovative Technology and Exploring Engineering, Vol 8, Issue 7, 2019, pp 120-125.

[36] P. Raghavaendra Rao, CH. Deepthi, M Venkateswara rao, Design and Analysis of Multi-Band Metamaterial Antenna for Wireless and IOT Applications, International Journal of Recent Technology and Engineering, Volume-8, Issue-1, May 2019, pp 334-340.

[37] M. Venkateswara Rao, T Naveen, N Sai Prashanth, B Niharika, Metamaterial Loaded Rectangular Monopole Antenna with Ultra-Wideband Applications, International Journal of Recent Technology and Engineering, Volume-8, Issue-1, May 2019, pp 1573-1576.

[38] P Saleem Akram, P Ganesh, G Srinivas, S Salma, Investigations on Metamaterial Slot Antenna for Wireless Applications, International Journal of Recent Technology and Engineering, Volume-8, Issue-1, May 2019, pp 709-713.

[39] M. Purna Kishore, S.S. Mohan Reddy, Metamaterial Inspired Gain Enhanced Elliptical Curved CPW fed Multiband Antenna for Medical and Wireless Communication Applications, Biomedical \& Pharmacology Journal, Vol 12, No 2, June 2019, pp 729-737.

[40] M Purna Kishore, M Venkateswara Rao, Metamaterial Loaded Elliptical Ring Structured MIMO Antenna, International Journal of Engineering and Advanced Technology, Vol 8, Issue 6, August 2019, pp 1798-1801.

[41] Merli. F, L. Bolomey, Meurville. E, and Skrivervik. A.K, "Implanted Antenna for Biomedical Applications", IEEE Antennas and Propagation Society International Symposium, San Diego, CA, 1-4, 2008.

[42] K.S.Sultan, H. H. Abdullah, and E. A. Abdallah "Low SAR, Simple Printed Compact Multiband Antenna for Mobile and Wireless Communication Applications" International Journal of Antennas and Propagation Volume 2014, Article ID 946781.

[43] Velan, S., Sundarsingh, E. F., Kanagasabai, M., Sarma, A. K., Raviteja, C., Sivasamy, R., \& Pakkathillam, J. K. (2014). Dual-band EBG integrated monopole antenna deploying fractal geometry for wearable applications. IEEE antennas and wireless propagation letters, 14, 249-252.

[44] Deepak, U., Roshna, T. K., Nijas, C. M., Vasudevan, K., \& Mohanan, P. (2015). A dual band SIR coupled dipole antenna for 2.4/5.2/5.8 GHz applications. IEEE Transactions on Antennas and Propagation, 63(4), 1514-1520.

[45] Xu, L. J., Duan, Z., Tang, Y. M., \& Zhang, M. (2016). A dual-band on-body repeater antenna for body sensor network. IEEE Antennas and Wireless Propagation Letters, $15,1649-1652$.

[46] Kang, D. G., Tak, J., \& Choi, J. (2016). Dual-band on-body antenna for in-on-on WBAN repeater
Published Online 1-4-2021

applications. Microwave and Optical Technology Letters, 58(2), 436-441.

[47] Saygin, H., V. Rafiei, and S. Karamzadeh, "A new compact dual band CP antenna design,"Microwave and Optical Technology Letters, Vol. 60, No. 3, 594-600, 2018. 